\title{
LA ESCRITURA NO ES SÓLO LENGUAJE
}

"...La forma es, quizás, un error de tussentidos, la substancia una imaginación de Iu pensamiento... A menos que, siendo el mundo un fluir perpetuo de las cosas, la apariencia sea, por el contrario, lo más verdadero; la ilusión, la túnica realidad..."

\section{Gustave Flaubert, La Tentación} de San Antonio, 1874

No sólo la cultura europea, también la cultura universal, ha sentido la presencia intelectual de Roland Barthes (1915-1980). Sus aportes en el estudio del fenómeno literario, desde la aparición de EL GRADO CERO DE LA ESCRITURA (1953) hasta EL DISCURSO AMOROSO (1978) posibilitaron el desarrollo del estructuralismo y una nueva forma de apreciar y valorar las creaciones verbales, las obras-producto de la escritura, sentando una seminal perspectiva para el análisis y comprensión de los discursos culturales producidos por la humanidad.

Su labor en la Escuela de Altos Estudios de Paris, en el Seminario de Sociología de los Signos, Símbolos y Representaciones, o su colaboración en el Centro de Comunicación de Masas (CECMAS), así como su papel de "guia espiritual" de las revistas Tel Quel, Communications, Langages, y Critique, han dejado una estela para explicar la vida contemporánea (cultura de signos) a partir de los conocimientos proporcionados por la Lingüística y la sucedánea Semiótica.

Roland Barthes (1) es uno de los "grandes" del siglo XX, junto a George Lukács, Roman Jakobson, A.J. Greimas, Luciem Goldmann, entre otros pensadores europeos que, desde la segunda mitad del presente siglo, agitaron el planeta con sus estudios literarios o lingüísticos.

Una idea clave del ideario barthiano es que el texto (obra literaria), por naturaleza, es plural y ambiguo; consecuentemente, su estudio e interpretación no pueden ser absolutos o definitivos, y su significación deviene, también, en múltiple y plural. Otro concepto innovador es el de "escritura".

Hoy lo podemos entender como una de las más grandes aventuras o empresas del intelecto humano, tanto en su punto de inicio (creación), en su proceso (producción), en su comprensión (recepción) y en su caracterización (escribiencia).

1. Licenciado en literatura y lingüistica. $\mathrm{Ha}$ traducido del francés, el presente diálogo entre Roland Barthes y Maurice Nadeau, recordando los cuarenta años de EL GRADO CERO DE LA ESRITURA (Edit. Seuil, París-Francia, 1953). Extraido de: ECRIRE... POUR QUOI? POUR QUI? (Edic. Universidad de Grenoble, París, 1973). La caricatura pertenece a la pluma del artista arequipeño Omár Zevallos Velarde.

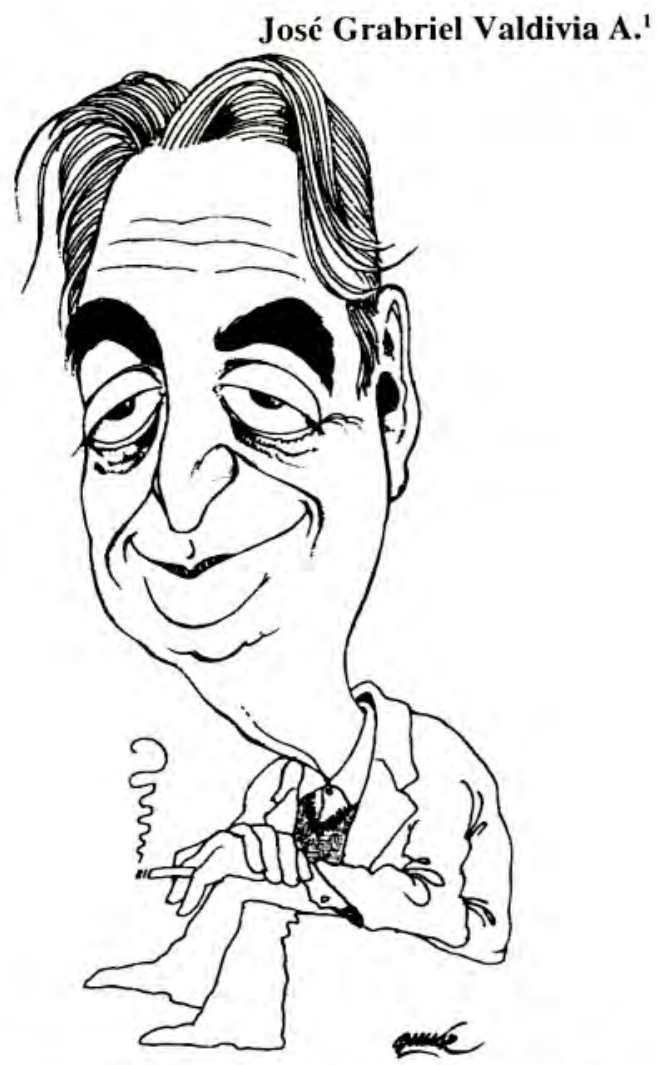

La presente entrevista tiene años de andar rondando nuestra francofonía y contiene las prospecciones del genial escritor francés - desaparecido inesperadamente en los inicios de la década pasada- en un ameno diálogo con Maurice Nadeau (2). Por él discurren algunas profecias en torno a que la literatura no desaparecerá, siempre y cuando se suprima la ruptura entre escritor y lector. Así surgirá una nueva utopía de la lectura, de la circulación de los textos, de la obra vista como una infinita "página amorosa".(J.G.V.).

\section{LA LITERATURA DEBE SER PENSADA COMO LENGUAJE}

Roland Barthes: Honestamente, no comprendo la pregunta: ¿a dónde va la literatura? Es una pregunta capciosa, como todas las preguntas prospectivas...Si quisiera responder inmediatamente, diría a su ruina, pero el debate quedaría concluido...Tenías una cita de Blanchot al respecto.

Maurice Nadeau: Blanchot ha respondido a la pregunta diciendo que la literatura va hacia ella misma, precisando que: va a su esencia, a su desaparición. "Desaparición" tiene, para él, una connotación metafísica, pero se nos 
pide responder a una pregunta más concreta: ¿dónde está actualmente la literatura? Ni tú, ni yo, somos profetas. Por mi parte, no sé adivinar dónde va. La pregunta no sería más amplia y equivaldria a decir: ¿qué es la literatura?

R.B.: Sería necesario, al terminar la entrevista, hacernos la pregunta: ¿dónde debe ir la literatura?... es decir, hacernos la pregunta de su utopia...

Antes, es necesario explorar algunos aspectos de la literatura como objeto...Es un concepto extremadamente confuso y amplio que ha variado mucho con el tiempo. La palabra "literatura" es muy reciente en el plano terminológico, su existencia data del siglo XVIII; antes se hablaba de las Letras o de las Bellas Letras, y esto era otra cosa.

También es necesario ubicar la literatura en su contexto social, para no equivocarnos en la manera de verla actualmente. Esto es muy importante, porque la literatura no es un objeto ni un valor intemporal, sino un conjunto de prácticas y valores ubicados en una sociedad dada.

\section{M.N.: Entonces, vamos a hacer un historial de la palabra y de la cosa.}

R.B.: Quizás. Primeramente debo decir que no acepto la palabra LITERATURA, preferiría hablar de ESCRITURA o de TEXTOS. Para mí, la literatura viene del mundo del lenguaje en que nosotros vivimos, y esta logosfera, determinada por lo que es nuestra sociedad, está profundamente dividida; en consecuencia, los lenguajes también están divididos. Es cierto que existen lenguas de carácter nacional, pero que no tienen en el fondo realidad social alguna, salvo a nivel de la gramática y de su enseñanza normativa. En realidad, hay varias lenguas dentro de una lengua nacional; creo que es necesario ubicar bien a la literatura en esta división de lenguajes.

M.N.: Sin duda, pero si la literatura es un lenguaje, es el lenguaje de varios y diferentes lenguajes. Ahora bien, si es particular, no se confunde con otros lenguajes particulares, como el de las profesiones o el de otros campos del saber. No existe un lenguaje literario, una literatura que parta de un trabajo sobre lo que se Ilama comúnmente lenguaje.

R.B.: Sí, pero esta particularidad data de mucho tiempo. En la sociedad francesa-hace dos o tres siglos- se ha atribuido al lenguaje literario una suerte de valor, de coartada trascendental, eterna, universal. El lenguaje literario era el lenguaje por excelencia, ya que en la realidad social habia una gran cantidad de lenguajes que, actualmente, están separados de la literatura.

En consecuencia, el lenguaje literario tiene una posición excéntrica, en relación a todos los lenguajes reales y, al mismo tiempo, una posición trascendente: como si fuera una síntesis de todos los lenguajes. Hay una suerte de puerta falsa que hace que la literatura esté, a menudo, amenazada por los grandes acontecimientos sociales; porque existe una socialidad: una ideología del lenguaje literario...La socialidad de la literatura se aprehende cuando se piensa que la literatura es lenguaje, no un vehículo de contenidos y representaciones.

M.N.: Se podría llamar un lenguaje literario de época. Pero entre todos los que utilizan este lenguaje, existen plenas diferencias, como las que separan a Racine de Campistron. ¿No sería mejor aprehender el problema a nivel del que escribe? Es un individuo aislado que se ubica en algún sector y utiliza, para cierto fin, un lenguaje que no es el de todo ei mundo y que llega a ser un lenguaje literario al final de su trabajo. ¿Soportando todas las determinaciones que sugieres; no se entrega, al menos, a un trabajo solitario? Se puede considerar este trabajo, desde el inicio hasta el final, como un proceso que elabora un producto original, y es la originalidad del producto la que gusta al lector... La actitud del lector-ya que la obra es un objeto de deleite y de placer- no es la del crítico, preocupado más en comparaciones, filiaciones, generalidades, ¿tampoco son dos actitudes inconciliables?

R:B.: He planteado el problema de la socialidad de la literatura, porque quisiera llegar, poco a poco, a interpretar el carácter específico, "tópico", de la literatura, que es algo muy especial y particular. Si tomamos, p. ej., una novela tradicional de Balzac, ¿en qué este relato participa de cierta socialidad?

Esto ha sido estudiado por críticos y por escuelas de críticos. Su participación es de un modo ambiguo, contradictorio. De un lado, el relato está concebido, globalmente, en un lenguaje muy particular, el lenguaje de la literatura, el lenguaje del relato escrito; no es un lenguaje 
hablado. Al mismo tiempo, al interior del relato, circulan y se presentan -en una forma caleidoscópica- una gran cantidad de lenguajes imitados.

Lo que hay de interesante en la literatura, no es el hecho de que un relato refleje una realidad social. El carácter específico de una obra literaria, de un relato, es practicar una "mímesis" de lenguajes, una suerte de imitación general de los lenguajes. Esto hace que la literatura -el relato- se dé como escritura literaria y sea, finalmente, la escritura literaria anterior la que copiamos.

La práctica literaria no es una práctica de la expresión, de la expresividad, de la representación; sino de imitación, de copia infinita. Es por ello que es un objeto muy difícil de definir: porque es un objeto de lenguaje. En el fondo, el lenguaje, aunque aparentemente esté de moda hace 20 años, es un ente de reflexión al que nos resistimos mucho; porque ello nos pone inmediatamente a hablar de nosotros mismos. Existe -a menudouna censura hacia el lenguaje y una censura hacia la literatura pensada como lenguaje; al menos a nivel de la opinión corriente.

M.N.: Me parece que diluyes fácilmente la originalidad de la obra en vastas entidades: la literatura, la socialidad... Si yo insisto en el nacimiento del acto literario, en la producción de la escritura, es porque veo en todo escritor un individuo que rechaza acercarse al lenguaje común -sin decirlo- y que recha$z a$, igualmente, todo lo que se ha escrito antes de él. La literatura nace cada vez que un individuo escribe con la voluntad de abolir toda literatura anterior. ¿Por qué escribir? Puede que el escritor imite, pero a pesar suyo e inconscientemente.

R.B.: Sin duda, pero hasta ahora la literatura lo recompensa siempre.

M.N.: Ella lo recompensa al final. Pero el acto por el cual se escribe, no sería un acto de copia. Escribir es lo contrario, instalarse en el rechazo, la soledad, la recusación de toda escritura anterior que parece falsa, inadecuada, insincera, literaria, en el peor sentido de la palabra.

R.B.: Sí, pero es una coartada.

M.N.: La coartada que permite el acto y que, en todo caso, no ha existido como coartada.
R.B.: Sí, pero escribir es ubicarse en lo que llamamos un inmenso "intertexto", es decir: ubicar su propio lenguaje, su propia producción de lenguaje en el infinito mismo del lenguaje.

M.N.: Puede ser, si consideramos las cosas del exterior. ¡Qué fin tan exaltante: desaparecer en el lenguaje! Aunque el escritor quiere hacer aparecer lo suyo y no parecerse a ningún otro.

R.B.: Pero ¿por qué no sería exaltante? Lo que se produce es una suerte de golpe al sujeto. $Y$ el golpe al sujeto, el golpe a la consistencia del sujeto, que se produce en la escritura, es tan exaltante, que se parece al de todas las experiencias límite, marginales, como la droga o la perversión.

Para mí, la literatura -me refiero a una literatura ejemplar, ejemplarmente subversiva, o mejor dicho la escritura, es siempre una perversión, una práctica que tiende a estremecer al sujeto, a disolverlo, a desaparecerlo en la página misma.

Durante mucho tiempo, debido a la ideología de la representación, de la figuración, esto se ha dado en las obras clásicas de un modo desviado, pero en realidad había ya en ese momento cierta perversión en la escritura.

Uno de los relatos más vertiginosos de la literatura francesa, porque condensa verdaderamente todas las problemáticas, es LE BOUVARD ET PECUCHET de Gustave Flaubert. Este es un relato de la copia, el emblema mismo de la copia en todas sus partes, puesto que Bouvard y Pécuchet son copistas... y la novela es una especie de carrusel de lenguajes imitados. Es la locura misma de la copia: los lenguajes se imitan, a menudo, los unos a los otros; no hay fondo original y espontáneo en el lenguaje: el hombre está perpetuamente atravesado por los códigos, de los cuales jamás toca el fondo. La literatura es, en algo, esta experiencia.

\section{LA LITERATURA ESTA EN CRISIS}

M.N.: La obra no sólo puede ser considerada como un sistema de lenguaje, donde juegan todas las figuras de la Retórica. Esto es atenerse al nivel superficial de la obra. ¿Qué hay de la voluntad, del deseo consciente o inconsciente del que escribe? Por ejemplo, SARRASINE ha sido enriquecido con tu comentario. Pero ¿dónde está en S/Z (Edic. 
Seuil, París, 1970. Col. Tel Quel) el deseo de Balzac de escribir SARRASINE? ¿Por qué dicha obra? ¿Con qué objeto? Nos quedamos en la suposición, en la vaguedad, si la tomamos únicamente, en el análisis de los significantes.

R.B.: Tu pregunta supone que en determinado momento ha habido una persona, un sujeto llamado Balzac, que ha dado a luz un producto: SARRASINE. Diria mejor que: ha existido un cuerpo que ha tenido la pluma. Es muy importante suponer la existencia de un escritor y de su escritura. Hay un dominio específico para explorar a Balzac: las correcciones sobre sus borradores y las pruebas de la imprenta. En esos momentos, había mucho más libertad y se podía hacer más de una docena de pruebas de un mismo texto. Contrariamente a la mayoría de escritores franceses, Balzac añadía nuevas cosas en lugar de suprimir.

\section{M.N.: Proust igualmente...}

R.B.: Sí, Proust, Stendhal, Rousseau, Balzac. Y cuando vemos las últimas pruebas de CESAR BIROTTEAU resulta admirable, puesto que es una página imprimida con explosiones. Es como un fuego artificial de supresiones, agregados (lo que Proust llamaba "paperolles"). Esto tiene verdaderamente una belleza plástica, que lo convierte, finalmente, en un emblema de la escritura; en una proliferación, en una discriminación, a lo largo de la página en blanco. Para mí, el autor sólo existe en el momento en que produce, y no cuando ya ha producido. En mi modesta carrera lo he sentido profundamente: una vez que he escrito un libro y ha sido publicado, no tengo nada más que decir, estoy desligado de él y no tengo relación alguna de propiedad o de gestión. Pero es el momento que la sociedad escoge para hacerte hablar de él.

M.N.: Sí, pero se reconoce a Barthes en LE PLAISIR DU TEXTE (1973) como en S/Z (1970). Son dos obras salidas de la misma pluma. Tienen un denominador común.

R.B.: Hay fenómenos que se llaman ideolectos; hay un ideolecto que es la presencia del cuerpo. El cuerpo no es personal, pero es individual. El cuerpo aparece de cierta manera en la escritura; en consecuencia, hay efectivamente ideolectos del escritor. Pero es necesario continuar atacando a este mito que ubica en un costado, anteriormente a la obra, a un sujeto, a una persona que se convierte en el padre, en el propietario de un producto: la obra. $Y$ en otro costado a la mercadería, la obra.

M.N.: Esto quiere decir que es el lenguaje escogido por el escritor y no lo contrario. En suma, una gracia que le cae del cielo. Un mito en remplazo de otro.

R.B.: El escritor escoge la forma de combinar. El combina las citas que pondrá entre comillas.

M.N.: ¿No existiría entonces más que combinadores?

R.B.: Sí, aunque esta fórmula pertenece a la época heroica del estructuralismo. Lo que nosotros podríamos hacer ahora, es ver los aspectos actuales y propiamente críticos de la literatura (recordando que la palabra "crítica" es un adjetivo que va con la palabra "crisis").

M.N.: Estamos de acuerdo en que la crisis existe. Desde que yo ejerzo mis actividades, siempre he escuchado hablar de crisis. Crisis de la edición, crisis de las librerías, crisis de la lectura. ¿No se trata de una situación endémica?

R.B.: Hay una crisis de la novela, también una crisis de la poesía, etc.

M.N.: En 1880 se realizó una encuesta entre los escritores. Todos hablaban de la crisis de la novela (Jules Renard incluído). La novela no estaba en crisis, sino que estaba muerta. Era el momento que Zolá producía su obra. Todos sabemos que Paul Valery, Paul Claudel, André Gide, no han querido escribir novelas. No era un género artístico; sin embargo, después de casi cien años, se ha asistido al nacimiento de no malos novelistas.

R.B.: Diría que, ahora mismo, hay crisis. Una crisis no tiene lugar cuando se produce menos objetos, menos libros; se produce, al contrario, cada vez más. En lo que concierne a la novela, se produce de todo y en la misma cantidad... Hay crisis cuando el escritor está obligado a repetir lo que ya está hecho, o bien, a dejar de escribir cuando está tomado poruna alternativa draconiana: repetir o retirarse.

M.N.: En este caso, no sería más que un copista. ¿Cabría la posibilidad de decir otra cosa?

R.B.: No. El no puede copiar. Pero, de todas maneras, la copia debe ser diseminante, pluralizada. No se copia obras, se copia lenguajes...Pienso, por 
ejemplo, que esta definición puede convenir efectivamente para remontarnos a la tragedia francesa. En el siglo XVIII, se puede decir que hubo una crisis de la tragedia, no porque había menos tragedias -había muchas- sino porque ellas se contentaban con repetir las tragedias que ya se habian dado. Es una situación que se puede trasladar a la novela y a la poesía. ¿En la novela, hay innovaciones, cambios?

M.N.: Dicen que el género ha evolucionado. Sobre una novela, no es necesario colocar el rótulo de "novela".

R.B.: No se pone más "novela" cuando son novelas; pero cuando no son novelas, se puede colocar "novela".

M.N.: Exactamente. Es decir que nosotros asistimos a una subversión de los géneros. Hay quienes ensayan caminos nuevos. Lo nuevo tiene un valor de choque, de ruptura, en tanto que rechaza una tradición que no es más que una forma de repetir, de inscribirse en la corriente de la literatura. Hoy es una explosión, una gran fiebre, el rechazo a todo nivel, aun al de la propia sintaxis. Se fabrica "textos" que no son novela, poesía; que son las dos, y que, a menudo, también derrotan al lector desprevenido.

Sé bien que la obra tiene otros fines más que el de la comunicación inmediata, pero es necesario, sin embargo, que dentro de diez o veinte años se diga que estos "textos" eran las grandes obras de la época. ¿EI ULISES de James Joyce, no ha sido letra muerta para los contemporáneos del escritor?

R.B.: Es un problema casi insoluble. Hay siempre una intimidación por la modernidad que no se puede evitar. La innovación es intimidante, porque se tiene un temor de fracasar en lo que puede ser importante en ella. Pero se debería ser objetivo y pensar en la modernidad en su conjunto, asumiendo la parte de sus derechos que inevitablemente comporta y que no podemos evaluar exactamente ahora. Es necesario tener una actitud de disponibilidad.

M.N.: Es necesario, igualmente, pensar en la famosa barrera de la edición, de la publicación. Son los editores, por lo general, quienes quisieran no habérselas más que con los copistas. Los copistas con hábito nuevo, naturalmente.
R.B.: Así es, sin embargo se edita libros ileíbles.

M.N.: Los libros de los cuales se dice "es ileíble", son los que al momento de ser publicados no tienen lectores, o muy pocos lectores. Sin embargo, el libro está allí, él madura dulcemente. Diez años más tarde es reeditado en libro de bolsillo. Lo constato en mis autores reputados como “ileíbles". Lo que nos parece incomprensible hoy, deviene después en muy leíble. Hay una conveniencia del lector en este aspecto.

R.B.: Encontramos, de otra parte, un viejo mito reaccionario, que opone lo intelectual a lo popular. En mi vida, me ha tocado defender a fondo -en un momento donde nadie lo hacía- una gran obra popular: el teatro de Bertold Brecht.

No pido que en Francia, próximamente, tengamos novelas correspondientes al teatro de Brecht. Esta no es una posición totalmente intelectualista, sabiendo que Brecht era un hombre inteligente, que hacía el papel de intelectual. Pero ha escrito un teatro para el gusto de sus espectadores.

¿Qué es lo popular? Si quisiera hacer de crítico: ¿qué sería la crítica popular? y ¿qué la crítica pequeño burguesa? Ella existe. No es posible, pero estamos en una sociedad dividida; yo mismo sufro la crueldad de esta división.

Pero es necesario comprender también que el hecho de aceptar escribir algo leíble, supone ciertas concesiones. La lengua no es inocente, y si se escribe algo leíble, se acepta cierta mediatización de su propio lenguaje. Esta concesión no se la puede aceptar, si se tiene verdaderamente una suerte de moral secreta, de táctica, de trampa implícita; una suerte de visión demasiado retorcida de lo que se quiere hacer con lo escrito... Se hace cierta concesión sobre el plano de lo leíble, porque se quiere hacerpasar cosas que parecen importantes.

M.N.: Son, en efecto, las dos orillas de la escritura. La primera, la de la cultura, de la tradición, de la leibilidad; y la otra, una pérdida de lenguaje, de vida. Se ve muy bien, lo de George Bataille, o lo de Antonin Artaud, aunque Artaud abandona el dominio del sintagma, de la frase, por el del grito.

R.B.: La escritura de Artaud está ubicada en un nivel de incandescencia, de incendio y de transgresión; en el fondo, no hay nada que decir de él. No 
hay crítica que hacer de Artaud. La única solución sería escribir como él, plagiarlo.

Y siempre, a propósito de esta idea de crisis: un hecho patente, actualmente, si se compara globalmente la literatura en Francia, hace unos treinta años -antes de la última guerrase constata un abandono, de alguna manera nacional y social, de la gran literatura y de su mito.

M.N.: ¿Un abandono también del mito del escritor?

R.B.: Igualmente, porque ahora ningún escritor tiene el lugar que tenían personas como: Valéry, Gide, Claudel, o como el mismo Malraux en nuestra época.

\section{LITERATURA Y COMPROMISO}

M.N.: Dentro de algunos días aparecerán los cuadernos de Mme. Théo Van Rysselberghe, quien ha vivido cerca de Gide. Ella consigna todos los hechos y gestos de Gide -en el curso de una jornada- sus palabras, los pensamientos que le ha confiado. Con esta nueva Eckermann, el mínimo comportamiento de Gide, la palabra más insignificante, revisten una significación. No querrá Sartre tener su Eckermann, o su Van Rysselberghe.

R.B.: El ha tenido a Simone de Beauvoir.

\section{M.N.: Sí, pero ella ha trabajado mucho por sí misma.}

R.B.: Cierta "liberación femenina" ha intervenido: nosotros hemos matado -felizmente- lo que Mallarmé llamaba "el Señor que está en el escritor", por no decir, "el señorito que está en el escritor". Hay en todo esto una transformación ideológica, social... Lo que se llama comúnmente burguesía, no sostiene más su gran literatura. Ella no tiene, en el fondo, su literatura. $Y$ esta gran literatura burguesa aparece, ahora, refugiada en las Academias, en los Parques Nacionales de Reserva. Es, desde luego, un abandono de los grandes "leaderships" de la literatura. Hay algunos "leaderships" más caóticos, más alocados, intranquilos, pero que son, de hecho, "leaderships" intelectuales y no propiamente literarios.

El gran fenómeno sociológico ocurrido hace unos treinta años-en la casta de escritores, es el advenimiento masivo de los profesores. Se crea consecuentemente, una nueva categoría de producción, a la vez literaria e intelectual, y que implica posiciones de compromiso político e ideológico; pero al mismo tiempo, una práctica de escritura.

A propósito del compromiso, quisiera precisar lo siguiente: ¿cómo es posible imaginar el compromiso en el problema del mundo?; de otra, ¿cómo comprometer una actividad que parece gratuita, no comprometida, de puro placer?

Se puede responder a través de una opción de tipo filosófico, comprendiendo bien que no se admite la contradicción. Personalmente sostengo, firmemente, la posibilidad de una conducta y de una práctica plurales. De una parte, admito coincidir profundamente, en lo concerniente a los problemas de la época; pero, al mismo tiempo, no me creo obligado, por ella, de censurar la actividad erótica de la escritura. Es una opción: depende si se le toma con una filosofía monista o con una filosofía pluralista.

El compromiso con la escritura pasa por mediaciones y constituye una mediación. Es necesario aceptar la idea de una práctica mediata, de una práctica mediatizada. Se puede pensar que nos comprometemos con la historia, por un trabajo sobre la escritura; pero evidentemente, no nos comnprometemos más que con una historia demasiado larga, prolongada; no nos comprometemos con la historia presente, inmediata, porque si quisiéramos comprometernos -por la escritura-con la historia presente e inmediata (con las crisis que nos rodean), encontraremos grandes dificultades, obligándolos a ustedes, a tener que pasar por el relevo de un lenguaje estereotipado que, precisamente, no sería nunca una escritura.

Yaquí defiendo la posibilidad de una filosofía pluralista, que parta de una autocontemplación como sujeto, y de comprometer, absolutamente, una parte de sí mismo en la vida contemporánea. De otro lado, comprometer -otra parte- en una actividad de escritura que se sitúa sobre otra longitud histórica, pero que permanece histórica, prospectiva y estimulada por una suerte de dinamismo progresista de liberación.

M.N.: Hay algunos casos donde el compromiso con la escritura puede coincidir con un compromiso político. Pienso en Soljénitsyne: un escritor comprometido con su escritura, sin que sus obras sean de propaganda, de polémica, etc. Por ejemplo EL PRIMER CIRCULO, PABELLON DE CANCEROSOS, son novelas 
comprometidas políticamente. ¿Cómo se hace para que una obra literaria, donde el autor se compromete, es decir cuando no hace política, coja de pronto un valor de subversión en cierta sociedad, excepto en la democracia burguesa? Lo que decías hace poco es verdad para nuestras sociedades $y$ no lo es para otras.

R.B.: Cualquiera que sea la importancia de Soljénitsyne, su escritura es muy tradicional, su escritura en sentido amplio; es decir, en la composición misma. En Francia, en el siglo XIX, hemos tenido una gran cantidad de novelistas que se comprometieron mucho más y que hoy no se les considera. Diría que la novela francesa del siglo XIX tiene un valor de testimonio, de diagnóstico, extremadamente cruel sobre la burguesía de la época. Las novelas actuales, tradicionales, no tienen esta especie de energía testimonial sobre las clases dominantes. Desde este punto de vista, Zolá se ubica mucho más adelante de lo que nosotros creemos. Lo que me parecería interesante preguntarnos es: ¿porqué no tenemos hoy, paralelamente a los textoslimite, a los textos de experiencia, una literatura verdaderamente realista, que describa de una manera crítica, desmitificante, la sociedad en la que estamos y que no la queremos.

M.N.: Esto puede ser verdad para la literatura en Francia. Dentro de la literatura latinoamericana, por ejemplo, asistimos, hoy, a una renovación de las técnicas novelísticas y a una puesta en escena de las realidades sociales. Es decir, a ese compromiso total que pasa,primero, por el compromiso de la escritura.

R.B.: A partir del momento en que hay práctica de escritura, se está ante cualquier cosa que no es más que literatura, en el sentido burgués del término. Yo llamo a esto TEXTO, es decir, una práctica que implica la subversión de los géneros. En un TEXTO no se reconoce la figura de la novela, de la poesía o del ensayo.

EITEXTO contiene, a menudo, el sentido; pero contiene, de alguna manera, el retorno del sentido. El sentido viene, va y pasa inmediatamente a otro nivel. Sería necesario retomar una imagen nietzscheana: la del eterno retorno del sentido. El sentido vuelve, pero como diferencia y no como identidad.

La noción de TEXTO se busca actualmen- te. Ha tenido antes, una suerte de valor polémico, era un concepto que se oponía al de OBRA. Dicho esto, no creo que ahora se pueda esperar dar una definición de la palabra TEXTO, porque se la tomaría bajo una crítica filosófica de la definición. Creo que, actualmente, esta noción de TEXTO no puede más que aproximarse metafóricamente, es decir, que se puede hacer circular, enumerar, inventar y enriquecer, lo más posible, las metáforas en torno al "TEXTO".(aunque Julia Kristeva haya ido muy lejos en la definición conceptual de TEXTO con relación a la lengua).

Sobre el límite del TEXTO no puedo responder: puedo distinguir la ESCRITURA de lo que he llamado la "écrivance" (escribancia o escribiencia), pero esto es esquivar la dificultad. La ESCRIBANCIA sería, en el fondo, el estilo del que escribe, creyendo que el lenguaje no es más que un instrumento y que no hay que debatir con su propia enunciación. La ESCRIBANCIA es el estilo de quien rehusa plantearse el problema de la enunciación y cree que escribir es simplemente encadenar enunciados; la ESCRIBANCIA se encuentra en muchos estilos: el científico, el sociológico. Hay de todas maneras estilos que se definen, a menudo, por la negativa del escribidor a ubicarse como sujeto de la enunciación: esto es la ESCRIBANCIA, aquí no hay TEXTO evidentemente.

Pero, de otro lado, y es por esto que retomaría las objeciones que me han sido hechas, no creo, del todo, que el TEXTO pueda definirse como un espacio aristocrático de escritura, porque en los periódicos, en las producciones de tipo masivo y "popular" no podría encontrarse el TEXTO bajo ciertas condiciones. Es necesario buscarlo. Personalmente no lo hago, porque mi generación está ubicada en la articulación de la literatura tradicional con la nueva literatura que se busca. Pero pienso que pronto se podrá revisar estas cosas, en parte éticas y estéticas, entre la buena y la mala literatura. Sabemos, desde ahora, que sería completamente estúpido, y casi criminal, postular una separación, por ejemplo, entre la escritura llamada demente y la escritura no demente; el verdadero límite se da entre la ESCRIBANCIA y la escritura; $y$ ha tomado el lugar del sujeto en la enunciación, sea que este lugar esté o no, asumido. El está asumido en la escritura; no, en la ESCRIBANCIA.

Escribir es un verbo intransitivo, al menos en nuestro uso singular, porque ESCRIBIR es 
una perversión. La perversión es intransitiva; la figura más simple y más elemental de la perversión, es la de hacer el amor sin procrear, ya que ella no delibera los productos. La escritura es, efectivamente, una perversión, porque en realidad, ella se determina desde el lado del goce.

En mi opinión, la producción literaria-en el sentido más amplio del término- está marcada cada vez más por un vacío, un hiato profundo entre una producción corriente que reproduce los modelos antiguos, a menudo con talento y sensibilidad para captar la actualidad, la sociedad, los problemas; y de otro lado, una vanguardia muy activa, marginal, muy poco leída, pero muy expe-rimentadora.

La nueva novela, por ejemplo, cualquiera que haya sido su interés, su importancia, su éxito, representa todavía una literatura demasiado tradicional -esto no es peyorativo-. Se ha podido hacer, recientemente, un análisis sociológico y estrictamente "goldmanniano" de LA ENVIDIA, como una novela de la decepción de la clase colonial, a punto de perder sus colonias. En este momento, se puede decir que Robbe-Grillet es un escritor comprometido. Pero en todo caso, en el plano de la escritura, la "nueva novela" es extremadamente leíble y no mueve verdaderamente la lengua. La nueva novela ha modificado ciertas técnicas de descripción y de enunciación. Ha utilizado las nociones de la psicología del personaje, pero no puede decir que representa una literatura límite, una literatura de experiencia. Las zonas intermediarias de la literatura, los escritores mediocres, los menores -en relación a los géneros- están llamados a desaparecer.

\section{LA LITERATURA COMO UTOPIA}

R.B.: Tengo cierta idea utópica de la literatura o de la escritura:la de una escritura feliz. Partiré de lo hecho hasta ahora -y sin hacer demagogia alguna con las palabras-. Desde el desarrollo de la democracia burguesa -hace aproximadamente ciento cincuenta años- hasta el progreso de las técnicas y de la cultura de masas, hay un divorcio evidente y terrible, a mi modo de ver, entre el lector y el escribidor: hay de un lado, escribidores o escritores; $y$ de otro lado, una gran masa de lectores. Y los que leen no escriben. ¿El problema está aquí, no es cierto? Los que leen no escriben.

Percibimos que en la sociedad anterior, socialmente alienada, donde la división de clases era extremadamente fuerte, este divorcio no existía a nivel de la clase feliz, de la clase ociosa. La prueba está en que la enseñanza secundaria dispensada a los hijos de los burgueses, a Flaubert por ejemplo, consistía en aprender a escribir. La retórica era el arte de escribir, mientras que ahora -en los colegios-se dice que se aprende a leer. Aprendemos cuando niños a leer bien, pero en el fondo no aprendemos a escribir. Ciertos sujetos -naturalmente numerosos y por definición clandestinos- tienen el deseo profundo de realizar este goce de la escritura y se chocan, naturalmente, con barreras terribles en el plano comercial, institucional, editorial. Pero la esperanza de poder escribir, incluso sin publicar, es un sueño que puede existir y que existía ya desde Flaubert, acaso con cierta mala fe...

Imagino entonces, una suerte de utopía donde los textos escritos en el goce, podrían circular fuera de toda instancia mercantil y donde, en consecuencia, no habría lo que se llama -de una manera muy cruel- una gran difusión. Hace veinte años, la filosofía era todavía muy hegeliana y jugaba mucho con la idea de la totalización. Hoy, la filosofía está muy pluralizada, en consecuencia, se puede imaginar utopias de tipo más grupuscular, más falansterianas.

Estos textos circularían en pequeños grupos, entre amigos -en el sentido casi falansteriano del término- en consecuencia, sería la circulación verdaderamente del deseo de escribir, del placer de escribir y del placer de leer, que harian una cadena fuera de toda instancia, sin juntar este divorcio entre la lectura y la escritura.

Cuando se ha comenzado a escribir, cuando se está en la escritura, cualquier cosa vale; por otra parte, llega un momento donde no hay tiempo de leer. Hay una especie de juego cruzado entre la escritura y la lectura que, en cierto momento, solo se llega a leer, lo que se tiene necesidad de leer para su trabajo. En consecuencia, la observación de los textos que aparecen en el año, por ejemplo, es una observación extremadamente funcional e interesada. Si un día debo preparar una intervención o un artículo sobre un sujeto dado, leo ciertos textos, ciertas obras. Personalmente tengo muy poco tiempo para la lectura en sí, para la lectura gratuita. Para ello empleo un poco la tarde -cuando regreso a casa- y también las vacaciones; pero en ese momento leo más los textos clásicos... Mi cono- 
cimiento de los textos modernos, entonces, deja de ser exhaustivo.

M.N.: Maurice Blanchot ha dicho que la Crítica era un no-lector. Un director de revista o de periódico, es un no-lector al cuadrado. Es decir que él lee todo sin leer. En realidad, la lectura en el oficio que yo ejerzo, no puedo hacerla; soy sólo un lector en los momentos donde no estoy obligado a leer.

R.B.: Se utiliza, en general, un precioso eufemismo. Se dice que se ha mirado un libro, no que se lo ha leído. Dicho esto, se podría admitir una suerte de muestreo de escritura, de una página o de diez páginas. Puedo afirmar que esto basta para establecer mi vínculo con el texto. Si se tiene para sí mismo, una relación erótica con la escritura, empalmada y articulada con el saber de las palabras, de las frases; con el saber de lo que se llamaba -en otros tiempos- el estilo, entonces, algunas páginas bastan.

De hecho, ahora, el gran problema es hacer del lector un escritor. El día en que se llegue a hacer del lector un escritor virtual o potencial, todos los problemas de leibilidad desaparecerán. Si se lee un texto, aparentemente ileíble en el movimiento de su escritura, se le comprende bien. Evidentemente que toda una transformación -diría que casi una educaciónestá por hacerse. Para esto es necesario un gran cambio social.

Lo mismo que sucedió en la pintura con "l'action-painting", considero para este caso, algo así como "l'action-writing", pero bien comprendi$\mathrm{da}$; donde haya también círculos numerosos para estos textos, de manera que no sean agredidos por los "textos" inoportunos, inadecuados.

M.N.: Partiendo de tus puntos de vista utópicos, veo con mucho placer tomar cuerpo a esta utopía. Hace algunos meses, recibí una carta de un dirigente de los trabajadores de la construcción. El escribía: "vuestro periódico distribuye el saber, el análisis, y nosotros leemos, somos consumidores. ¿Por qué no podríamos escribir en vuestro periódico?". Yo le he respondido, sin dificultad, que estoy completamente de acuerdo. En la Quinzaine Littéraire escriben muchos profesores, especialistas, aficionados refinados. Es que al obrero de la construcción que me ha escrito debo decirle: “¿vamos a ubicar un lugar en el rincón del periódico, vamos a confinarlos en un ghetto?". De otro lado, ¿quién va a hacer la selección de textos?, ¿según qué criterios? ¿Se necesita publicar un texto, porque revela sólo una cierta sinceridad en el relato de una experiencia, o porque accede ya a un nivel literario.

R.B.: Esto ha de estallar lleno de dificultades, porque la gente de que hablas, va a llegar a la escritura teniendo ya una cultura. El riesgo de que el texto sea una suerte de espacio expresivo, es para ellos. En realidad, sería necesario que ellos lleguen a comprender que el texto es un espacio seductor y que, en consecuencia, es necesario plantearse el problema de la seducción cuando se escribe. $Y$ seducir a alguien es toda una aventura. En otras ocasiones, la Retórica había pensado en la solución, porque ella ha sido, en gran parte, un arte supuesto de la seducción; pero ahora, ella no basta. El problema está, entonces, en saber lo que puede ser una seducción del texto hoy, ¿cómo concebirla, cómo hacerla comprender y, sobre todo, cómo admitir su necesidad en los que quieren escribir?

M.N.: ¿Pero por qué una sub-literatura no tendría derecho a existir?

R.B.: No, si ella fastidia. Yo tengo un poco de mala fe, porque lo que molesta a uno, no molesta a otro, etc. Es muy complicado. Pero, en todo caso, pienso que es necesario, poco a poco, plantearse el problema de lo erótico del texto. Los textos llamados eróticos no coinciden, a menudo, con una erótica del texto; es decir, un texto que intente inscribir el cuerpo del escribidor junto al cuerpo del lector y de establecer una suerte de relación amorosa entre estos dos cuerpos, que no corresponden a personas civiles, morales; pero sí a figuras, a sujetos desaparecidos, civilizados. En todo caso, la literatura no puede resolver, sola y por sí misma, sus propios problemas.

M.N.: En esto estamos de acuerdo desde el inicio de nuestra entrevista. La actividad de escribir se inserta entre las otras actividades sociales. Ella establece con el contexto social relaciones dialécticas y tiene la necesidad de saber la forma en que la sociedad se ayudará para ayudarse a sí misma.

R.B.: Es un problema de alienación social. Muchas estadísticas han dicho que Francia era uno de 
los pueblos que menos leía, puesto que uno de cada dos franceses no lee. Pero no es necesario ser tan riguroso. Si hay toda una literatura que no se lee, al mismo tiempo, se la conoce; es decir que ella toma, sin embargo, un valor de fecundación. He aquí un fenómeno sociológico nuevo, importante; por ejemplo, tenemos autores donde la notoriedad está dada por el tiraje de sus obras, yautores que tienen tirajes muy reducidos $y$ que, sin embargo, son conocidos inmediatamente en el gran público intelectual, donde cumplen una función, un rol.

La escritura no sólo se ejerce por su literariedad, por su captura, por la lectura, en un sentido propio; sino también, un poco, por ósmosis, por metonimia. Aquí se produce una especie de lectura paróptica, paracústica...

En tanto la obra será una página amorosa, se puede esperar que la literatura durará...

\section{NOTAS}

(1) BIBLIOGRAFIA DE ROLAND BARTHES: Le Degré Zéro de I'Ecriture (1953), Michelet por Sí Mismo (1954), Mythologies (1957, 1970), Sobre Racine (1963), Ensayos Críticos (1964), Critica y Verdad (1966), El Sistema de la Moda (1967), Elementos de Semiología (1964), S/Z (1970), El Imperio de los Signos (1970), Sade Fourier Loyola (1971), Le Plaisir du Texte (1973), Barthes por Barthes (1975), El Discurso Amoroso (1978), La Aventura Semiológica (1985), EI Susurro del Lenguaje (1985), Lo Obvio y lo Obtuso (1985), La Aventura Semiológica (1985);

(2) Maurice Nadeau, el otro protagonista del presente diálogo, ha sido director de las revistas: Lettres Nouvelles y la Quinzaine Littéraire. Ha escrito entre otros libros: Historia del Surrealismo (1945), Literatura Actual (1962), Michel Leiris et la quadrature du cercle (1963), Le Roman Francais depuis la Guerre (1964) y Gustave Flaubert, écrivain (1969)).

\section{APENDICE}

\section{MARIO VARGAS LLOSA Y ROLAND BARTHES}

M.V.LI.: ...Barthes es un crítico indudablemente creativo, aunque uno tenga que discrepar de él...

R.C.G.: ¿Sobre qué puntos discreparías fundamentalmente con él?

M.V.LI.: Me parece que Roland Barthes es un formalista, en el sentido tradicional de la palabra. La explicación formal es muy importante, pero parcial; y si se la exclusiviza puede llevar a un malentendido del fenómeno literario, tan brillante como el de un Barthes. Explicar la literatura únicamente a nivel de la escritura es mutilar el fenómeno literario, reducirlo a algo esquemático.
R.C.G.: Pormi parte, pienso que no se puede identificar la forma -en el sentido implícito en la dualidad forma/contenido-con la escritura que sería una realidad sobre la que el contenido y la forma incidirían, pero ya sin ser tales...No sé si me hago entender.

M.V.LI.: No creo que se pueda considerar la escritura como una realidad autónoma, en el sentido en que la entiende Barthes, y su exacerbación, la revista "Tel Quel". No me parece verosímil esa autonomía irreductible de lo estrictamente formal. La creación literaria reduce lo histórico a proyecciones y representaciones a nivel de la pura palabra, desde luego, pero ésta no agota el fenómeno literario, ni mucho menos. El de Barthes en cierto modo, es un enfoque semejante, aunque no idéntico al de la estilística, que estuvo en vigencia hasta hace algunos años (que sigue estando vigente, por ejemplo, en las universidades españolas). Esto a la larga lleva a una esquematización de la obra literaria que es más peligrosa en el caso de la novela. El ecumenismo característico de este género, su voluntad totalizadora de algún modo debe reflejarse en la crítica que se hace cargo de él. La crítica capaz de dar cuenta de esa universalidad, debe ser ella misma universal.

R.C.G.: Es necesario tener en cuenta que, en realidad, hay varios Barthes. El que hace crítica literaria propiamente dicha, el que estudia la moda a partir de supuestos lingüísticos (el semiólogo), el que hace de gurú de la escuela "Tel Quel"...

M.V.LI:: Me parece que el más sugestivo es el de MYTHOLOGIES y el de los ENSAYOS CRITICOS. En el momento en que pone en práctica sus teorías, las lagunas de éstas quedan superadas por la praxis. Por otra parte, no creo que exista ningún crítico que no viole sus propios postulados en la práctica... La relación entre el crítico y la materia prima por él utilizada es la misma que existe entre la novela y la realidad que expresa. Una novela puede ser profundamente infiel, desde un punto de vista histórico, sociológico o religioso, a la realidad y, sin embargo, ser una gran novela que expresa una verdad que no es la de la historia, la sociología, o la religión: una realidad más profunda, o simplemente distinta.

R.C.G.: Si me lo permites, te diré que con esta idea andas muy cerca de Barthes. El prólogo a los ENSAYOS CRITICOS gira más o menos en torno a una cierta simetría entre la relación del novelista con la realidad y la del crítico con la realidad de las obras del novelista...

(Tomado de: Ricardo Cano Gavidia, EL BUITRE Y EL AVE FENIX: Conversaciones con Mario Vargas Llosa. Edit. Anagrama, Barcelona-España, 1972). 